\title{
BMJ Awards South Asia 2016: how to find the best in South Asian healthcare
}

\author{
The $B M J$ is getting closer to identifying the best in South Asian healthcare for 2016, with winners \\ to be announced at a ceremony in New Delhi on 19 November, writes Jeetha D'Silva
}

\author{
Jeetha D'Silva, journalist
}

Mumbai

The rugged Leh district, in the Himalayan state of Jammu and Kashmir, has a remarkable healthcare story. Until a few years ago its people had no access to specialist healthcare-anything other than basic care required an arduous and expensive 400 km journey to Srinagar, the state's capital, or to New Delhi, which is over $1200 \mathrm{~km}$ away.

But since 2013 Leh's people have benefited from an annual camp run by doctors from the All India Institute of Medical Sciences (AIIMS) in New Delhi. The team includes orthopaedic surgeons who have been conducting complex procedures, such as total knee arthroplasty and hip replacement, at Leh's Sonam Norboo Memorial Government Hospital for less than Rs100 000, a fraction of the cost elsewhere.

Sumit Anand, a research fellow in the orthopaedics department at AIIMS, said that before these camps people might have spent almost Rs500 000 on knee or hip replacement surgery because the patient would have to travel to a tertiary hospital in another city. Most people in the Ladakhi region of the state had no option but to live with the pain of their condition.

Speaking to The BMJ from Leh, Chandra Shekhar Yadav, professor of orthopaedics at AIIMS and the surgeon leading the project, said that initially the hospital had inadequate infrastructure for specialist procedures. "We had to transport all the components required. We airlifted almost $1000 \mathrm{~kg}$ of implants and other equipment for the camps," he said.

\section{Stories of impact}

Despite these challenges, the team has performed more than 50 total knee and total hip replacements in total. This year the team set up a similar camp at Kargil, near the India-Pakistan border. These achievements have earned Yadav and his team a place among the semifinalists for Surgical Team of the Year at the BMJ Awards South Asia 2016.

Similar stories abound in the 2016 edition of the awards. This year 1523 nominations were received from Bangladesh, India, the Maldives, Myanmar, Nepal, Pakistan, and Sri Lanka—substantially more than last year's 900 entries. ${ }^{12}$

"People are recognising the BMJ Awards as a great way to project their work," said Prashant Jha, senior editor at The BMJ and editorial lead for the awards. He noted that many entries this year came from independent practitioners and small facilities, especially in cities classified as tier 2 or 3.

Research Paper of the Year was the most popular category, with 320 nominations, followed by the Postgraduate Thesis of the Year, with 250 entries. The Healthcare Innovation of the Year category received 203 entries, making it the third most popular category. This category has the largest number of shortlisted entries, with 31 semifinalists of the total 151 .

\section{Frugal innovation}

"This comes as no surprise, as we are known for 'jugaad' [frugal innovation]," Jha said. "Healthcare providers in our region face a lot of challenges. And where you have a lot of constraints, you have a lot of innovation."

The BMJ spoke to some of the shortlisted nominees in this category and found many innovative projects. The Neonatal Transport Project from Lady Ridgeway Hospital in Colombo, Sri Lanka's largest children's hospital, created a dedicated neonatal transport system at low cost.

Ramya de Silva, the consultant paediatrician in charge of the neonatal intensive care unit at the hospital and president of the Sri Lanka College of Paediatricians, told The BMJ, "Previously, pre-term babies and neonates who were brought from small and large hospitals were in poor condition, with the majority having hypothermia and hypoglycemia."

The team collaborated with Oxford University Hospitals in the UK to devise logistics, commission equipment, create protocols and policies, and train staff in referring hospitals. The project was initially implemented in the western province of Sri Lanka 
in 2013-14. "At the end of the first year we found that normal temperatures on admission were recorded in $89 \%$ of infants who used the new transport system versus in $20 \%$ of those who did not use it. None of the babies had hypoglycemia," de Silva said.

The project has been scaled up and a national neonatal transport system established. Now other countries in the region are planning similar systems. Sri Lanka has the lowest under 5 mortality rate in the region, with 10 deaths for every 1000 live births. India, by comparison, has 48 deaths for every 1000 live births, and Pakistan has $81 .^{3}$

\section{Mental healthcare}

Another innovative public health project is the development of mental healthcare for accredited social health activists (ASHAs) in India by the epidemiology team at the National Institute of Mental Health and Neurosciences (NIMHANS) in Bangalore. The team developed a model called IRIS-identify, respond, inform, and support - to help ASHAs tackle mental health problems in the community.

Senthil Amudhan, assistant professor in the department of epidemiology at NIMHANS, said that the stigma attached to mental health leads to delays in seeking treatment. The team developed a manual that prioritises mental health problems and held a training day using the manual translated into local language. Amudhan said that it was "useful in enhancing the mental health literacy and reducing the stigmatising attitudes of ASHAs." The team hopes that winning a BMJ Award will bring recognition to the IRIS model and enable it to be adapted for other non-communicable diseases.

\section{Think outside the box}

Shah Faisal Ahmad Tarfarosh, of Acharya Shri Chander College of Medical Sciences and Hospital in Jammu, thinks that the prestigious recognition of a BMJ Award will encourage more doctors to think outside the box. He was an undergraduate student when he and some friends devised a portable product to relieve lower back pain, which has been shortlisted for Healthcare Innovation of the Year. ${ }^{4}$

Most nominations for awards came from India; but 65 nominations came from Pakistan, 62 from Sri Lanka, 54 from Bangadesh, 46 from Nepal, and five and one from Myanmar and the Maldives, respectively. Pakistan has eight nominations in the first shortlist, Sri Lanka has seven nominations, Bangladesh and Nepal both have six, and Myanmar one; the rest of the shortlisted nominations are from India.

\section{Quality improvement}

One shortlisted nomination from Pakistan has been selected for Quality Improvement Team of the Year. Huzaifa Ahmad, an undergraduate student at Aga Khan University Hospital, explained to The BMJ that, before 2013 , teamwork was hindered by an "outdated traditional hierarchy, with surgeons and physicians playing the most active role while the nurses adopted a subdued presence."

After the cardiac intensive care unit joined the International Quality Improvement Collaborative in January 2013, the unit implemented guidelines from the collaborative to develop a "nurse empowered approach," Ahmad said, with a nurse leading the team. Surgical site infection and bacterial sepsis fell from $30 \%$ to $1 \%$ after implementation. Mortality rate fell from $9 \%$ to $6 \%$.

\section{Two new categories}

The BMJ Awards have two new categories: the Excellence in Delivering Primary Care award received 115 entries, and the Recognition for Promoting Integrity/Transparency in Healthcare award received 51 nominations.

One of the semifinalists in the Recognition for Promoting Integrity/Transparency in Healthcare category, ASHASoft, is an online payment and monitoring system developed by the government of Rajasthan for its accredited social health workers.

Naveen Jain, director of the government's national health mission, told The BMJ, "Rajasthan has 46000 ASHAs. Monitoring their work and ensuring that they are paid on time was often challenging as they are involved with many government programmes."

ASHASoft enables online payment of incentives to be made directly to health workers' bank accounts. The programme has reduced the wait for payment from 60 to 12 days. Fraudulent payments can be traced, and corruption has been reduced. ASHASoft can also monitor the workers' performance and highlight training needs.

\section{Screening by metrics}

The BMJ Awards South Asia 2016 are now in the second stage of eliminations. In the first phase entries were screened using metrics including relevance of the work to the South Asia region, ability to influence the practice of medicine, applicability to unmet need, novelty, scalability, patient involvement, and future plans.

The 151 semifinalists were announced on 18 September. ${ }^{5}$ They will now go through a second phase of screening, with 30 entries to be chosen as finalists. They will be invited to present their work to an expert jury on 18 November. Winners of the BMJ Awards South Asia 2016 will be announced on 19 November at a ceremony in New Delhi.

See http://southasiaawards.bmj.com, www.facebook.com/bmjindia and https://twitter.com/BMJIndia for more details.

Competing interests: I have read and understood BMJ policy on declaration of interests and have no relevant interests to declare.

Provenance and peer review: Commissioned; not externally peer reviewed.

1 D'Silva J. Stories of South Asian clinical excellence: who won the 2015 BMJ Awards?BMJ 2015;351:h5911. doi:10.1136/bmj.h5911 pmid:26538248.

2 D'Silva J. BMJ Awards South Asia 2015: judging South Asia's unsung healthcare heroes. BMJ 2015;351:h5305. doi:10.1136/bmj.h5305 pmid:26445977.

3 The World Bank. Mortality rate, under-5 (per 1000 live births). http://data.worldbank.org/ indicator/SH.DYN.MORT

4 Tarfarosh SFA, Lone BU, Beigh MI, Manzoor M. An innovative and portable multimodal pain relief device for the management of neuropathic low back pain—a study from Kashmir (Southeast Asia). Cureus 2016;8:e661.pmid:27493843.

5 Awards BMJ. South Asia. Results—phase 1. 2016. http://southasiaawards.bmj.com/resultphase-1/

Published by the BMJ Publishing Group Limited. For permission to use (where not already granted under a licence) please go to http://group.bmj.com/group/rights-licensing/ permissions 